J. Dairy Sci. 92:3915-3921

doi:10.3168/jds.2008-1823

(c) American Dairy Science Association, 2009.

\title{
Does a calf's motivation to ingest colostrum depend on time since birth, calf vigor, or provision of heat?
}

\author{
E. Vasseur, ${ }^{* 1}$ J. Rushen, $†$ and A. M. de Passillé \\ *Animal Sciences Department, Laval University, Quebec, Quebec, Canada, G1K 7P4 \\ †Pacific Agri-Food Research Centre, Agriculture and Agri-Food Canada, Agassiz, British Columbia, Canada, V0M 1A0
}

\begin{abstract}
Dairy producers often complain that calves have difficulty consuming the recommended amount of colostrum. A better understanding of factors affecting calves' motivation to ingest colostrum could help develop better management. Thirty-six Holstein calves were tested to evaluate effects of time since birth $(2$ vs. $6 \mathrm{~h}$ ) and provision of a heat lamp on motivation to ingest colostrum in a $2 \times 2$ factorial model. Calves were randomly assigned to treatments balancing for birth weight and sex. Calves were provided colostrum $(>68$ $\mathrm{g}$ of $\mathrm{Ig} / \mathrm{L})$ ad libitum from a teat-bottle. We tested the calf's suckling reflex by examining the response to orofacial stimulation and assessed the calf's vigor from the duration of time spent standing or attempting to stand in the hour after birth and standing during colostrum feeding. During the first meal, $42 \%$ of calves consumed $4 \mathrm{~L}$ or more of colostrum, $25 \%$ consumed 3 to $4 \mathrm{~L}, 11 \%$ consumed 2 to $3 \mathrm{~L}$, and $22 \%$ consumed $<2 \mathrm{~L}$. There were no significant effects of heat supply or time since birth on consumption. The quantity of colostrum ingested was best predicted $\left(\mathrm{r}^{2}=0.61\right)$ by a combination of birth weight, vigor during colostrum feeding, and vigor during the first hour of life, whereas meal duration was predicted $\left(\mathrm{r}^{2}=0.34\right)$ jointly by room temperature and having suckled the dam. Colostrum intake was lower for small calves and calves with a low degree of vigor. Differences among calves in the strength of the sucking reflex were not related to colostrum intake.
\end{abstract}

Key words: colostrum intake, hours of age, heat supply, calf vigor

\section{INTRODUCTION}

Dairy calf mortality and morbidity are high (USDA, 2007; Vasseur et al., 2008), and poor colostrum intake is one of the main causes (Wells et al., 1996). Up to $40 \%$ of calves are diagnosed as having failure of passive transfer (FPT; Filteau et al., 2003; Trotz-Williams et

Received October 22, 2008.

Accepted April 9, 2009.

${ }^{1}$ Corresponding author: elsa.vasseur.1@ulaval.ca al., 2008). It is recommended that calves ingest $4 \mathrm{~L}$ of colostrum within 4 to $6 \mathrm{~h}$ of birth but dairy farmers often report that calves have difficulty consuming the recommended amount. One possible reason for FPT is a low intake of colostrum due to calves' unwillingness to consume the recommended amount.

Calves' willingness to consume colostrum may be affected by the time since birth and cold stress. Calves are often housed in unheated buildings to improve health, but cold temperatures lead to increased calf mortality (Azzam et al., 1993) and an impaired absorption of immunoglobulins from colostrum (Olson et al., 1980; Norheim and Simensen, 1985). In piglets, cold stress also reduces colostrum intake (e.g., piglets; Le Dividich et al., 2005). Supplemental heating is rarely used with newborn dairy calves but has been found to be useful for resuscitating calves during the first $24 \mathrm{~h}$ (Uystepruyst et al., 2002).

The calf's vigor at birth could influence its willingness to consume colostrum (Herpin et al., 1998). Tests of vigor have been developed for various species (AlonsoSpilsbury et al., 2005; Veronesi et al., 2005) including calves (Zaremba et al., 1993). Poor vigor can result from anoxia due to calving difficulties (Wendy, 1999; Mee, 2004). Poor vigor at birth increases odds of death (Riley et al., 2004) or delayed suckling (Ventorp and Michanek, 1991). However, little is known about other indicators of calf vitality such as the strength of the sucking reflex or even how calf's vigor affects colostrum intake. In addition, calves that suckled from their dam may be less willing to suck colostrum from a bottle.

The objective of this study was to examine the effects of age ( 2 vs. $6 \mathrm{~h}$ ) and provision of a heat lamp on calves' voluntary intake of colostrum. We also examined the effects of calving difficulties, calf vigor, the strength of the sucking reflex, and prior suckling from the cow.

\section{MATERIALS AND METHODS}

\section{Calves and Treatments}

Nineteen male and 17 female Holstein calves (mean \pm SD birth weight: $46.7 \pm 7.1 \mathrm{~kg}$ ) were used. All pro- 
cedures were in accordance with Canadian Council for Animal Care (1993) guidelines and were approved by the local animal care committee.

The calves were semi-randomly assigned to the following treatments, balancing for sex, in a $2 \times 2$ design: colostrum feeding at 1 to $2 \mathrm{~h}$ after birth $(\mathbf{2 H}$ calves $)$ or colostrum feeding treatment at 5 to $6 \mathrm{~h}(\mathbf{6 H}$ calves $)$ after birth with (HL) or without a heat lamp (no HL) treatment.

Before calving, cows were placed in an individual calving pen $(3.4 \times 4.5 \mathrm{~m}$; straw bedding on sand $)$ in the main barn. The calf and dam were filmed from the moment of birth for $1 \mathrm{~h}$ (2H calves) or $5 \mathrm{~h}(6 \mathrm{H}$ calves) with one digital camera per pen [Panasonic WVBP334 CCTV (Secaucus, NJ); viewing and recording with Genetec Omnicast software (Saint-Laurent, Quebec, Canada) or VHS tape Fujifilm HQ 160 (Valhalla, NY), Uniplex Sprite multiplexer (Reston, VA), and Panasonic AG6730 recorder (Secaucus, NJ)]. The video records were used to determine time of birth and whether interventions were necessary to pull calves out during calving.

Although measures of calf vigor have not been standardized, a common approach is to define vigor in terms of the calf's ability to stand without assistance (Godfrey et al., 1991). Therefore, to score the vigor of the calf at birth, we noted during the first hour after birth, in each period of $5 \mathrm{~min}$ (presence $=1$, absence $=$ 0 ), if the calf was standing, walking, or attempting to stand. An attempt to stand was scored whenever the calf had been in a lying position and tried to stand by bending its front legs (1 or 2 ) with its back legs (1 or 2) stretched back. We also recorded if the calf suckled the cow, which we scored if the calf was in the sucking posture close to the cow's udder. The camera was not close enough to observe actual sucking movements. To estimate birth weight, calves were weighed (Western Scale Co., Vancouver, British Columbia, Canada) between 10 and $28 \mathrm{~h}$ after birth.

Calves remained with the dam in the calving pen until being moved into the calf barn at 55 to $70 \mathrm{~min}$ ( $2 \mathrm{H}$ calves) or at 4 to $5 \mathrm{~h}$ (6H calves) after birth. A motorized vehicle (Gator $4 \times 2$ John Deere, Moline, IL) was used to move calves from the calving pen to the individual test pens $(2.0 \times 1.1 \mathrm{~m}$, sawdust on concrete) in an isolated room of the calf barn. The ambient temperature (mean $\pm \mathrm{SD}: 6.4 \pm 2.8^{\circ} \mathrm{C}$ ) and relative humidity of the isolated room were recorded every minute using a data logger (Hobo ProV2 temp/ RH onset, Bourne, MA). Each calf's rectal temperature was taken at arrival in the test room with a digital thermometer (WelchAllyn SureTemp plus, Skaneateles Falls, NY). The calf's navel was cleaned and disinfected with iodine.
For the heat-treatment calves, a heat lamp (Satco indoor Red 250W S4998, Brentwood, NY; fixed in the middle of the pen; at $0.9 \mathrm{~m}$ of height) was turned on as soon as the calf was placed in the pen. Using a black globe thermometer (model 210-4417, Novalynx Corp., Grass Valley, CA), the lamps were found to provide heat so that a temperature of $28^{\circ} \mathrm{C}$ was recorded at the average height of the calf's back. All calves were left in the pen for $1 \mathrm{~h}$ so that they could adapt and rest before the tests began. The calves were filmed with a digital camera (Sony Handycam HDD DCR-SR100, New York, NY; fixed on a tripod) for the adaptation hour as well as during the sucking motivation and ad libitum colostrum intake tests.

Each calf was allowed to consume an ad libitum quantity of colostrum. To control for colostral quality among treatments, a pool of frozen colostrum was used for all calves of a block. A pool comprised $16 \mathrm{~L}$ of first-fresh colostrum collected from 1 to 4 cows or heifers. The quality of colostrum was measured by a colostrometer (Kruuse Colostrum Densimeter, Langeskov, Denmark) at $20^{\circ} \mathrm{C}$, and only colostrum with $50 \mathrm{~g}$ of $\mathrm{Ig} / \mathrm{L}$ or more was kept. On average, the pools of colostrum served to calves contained $77 \pm 13 \mathrm{~g}$ of $\mathrm{Ig} / \mathrm{L}$ (mean $\pm \mathrm{SD}$ ). One pool of $16 \mathrm{~L}$ was made up of $500-\mathrm{mL}$ samples frozen individually in ziplock plastic bags at $-17^{\circ} \mathrm{C}$ for at least $24 \mathrm{~h}$. Extra colostrum (4 L) of equal quality but of different origins was available in case some calves consumed more than $4 \mathrm{~L}$. For each calf, 12 bags each containing $0.5 \mathrm{~L}$ of colostrum $(6 \mathrm{~L}$ in total) were thawed by placing each bag in a larger ziplock bag that was placed in $40^{\circ} \mathrm{C}$ water for $20 \mathrm{~min}$. Once thawed, the colostrum was warmed to $20^{\circ} \mathrm{C}$ (temperature verified using a digital cooking thermometer PC MD 91646, Brampton, Ontario, Canada).

A standard procedure for giving the colostrum was followed for all calves. The calf was held up on its 4 legs in a back corner of the individual pen ensuring that the posterior of the animal was against the back wall of the pen and the calf's flank was against the left wall of the pen. The experimenter's left leg kept the flank of the calf against the wall of the pen. The experimenter's left arm was placed around the neck of the calf and the left hand was placed under the calf's jaw so the calf's head was held up. Colostrum was provided in 3 $\times 2$-L teat-bottles. The teat was not removed from the calf's mouth until the animal stopped consuming by itself. When the calf finished the 2-L bottle, a second 2 -L bottle was offered in the same manner. A third bottle was offered if a calf consumed all the first $4 \mathrm{~L}$. Only one calf was found to want more than $6 \mathrm{~L}$. The experimenter ended the test if the animal would not suck for $20 \mathrm{~s}$ when the teat had been kept in the calf's mouth. If the calf removed or tried to remove the teat 
from its mouth, the experimenter stopped restraining the calf and waited $2 \mathrm{~min}$ before re-introducing the teat into the calf's mouth. If the calf stopped consuming by itself twice in a row, the experimenter stopped restraining the calf and waited 2 min until re-introducing the teat into the calf's mouth. After 2 re-introductions, the experimenter considered the first meal finished.

We recorded the quantity of colostrum consumed and the duration of the meal. The feeding period was video recorded and the calf's position during each 5-min period of the colostrum feeding was recorded as able to stand or lying down.

To ensure that all calves ingested sufficient colostrum (and so to limit the risk of FPT), a second meal was provided $1 \mathrm{~h}$ after the end of the first meal to all calves that did not consume $4 \mathrm{~L}$ during the first meal. If the calf did not ingest a total of at least $3.5 \mathrm{~L}$ of colostrum after the second meal, the animal was force-fed using an esophageal tube (Jorvet TM 4L, Loveland, $\mathrm{CO})$. A blood sample was taken [10-mL serum Vacutainers (Becton Dickinson, Franklin Lakes, NJ) and 1-inch 20-gauge needles] at 24 to $48 \mathrm{~h}$ after the first colostrum meal from the jugular vein to determine the total protein content to check passive immune transfer and immune status of the calves. The sample was kept cold until centrifuged (at $769 \times g$ for 12 min) less than $24 \mathrm{~h}$ after sampling. The serum sample was read using a digital refractometer (Reichert AR200, Depew, NY) calibrated for serum proteins. The average serum proteins (an indirect estimation of Ig) was $6.0 \pm 0.5 \mathrm{~g} /$ $\mathrm{dL}$ (mean $\pm \mathrm{SD})$, with all calves exceeding $5.0 \mathrm{~g} / \mathrm{dL}$ (minimum value).

At 2 min before giving the colostrum, we tested the calf's sucking reflex using a procedure developed for sheep (Vince, 1984; Vince et al., 1984, 1991). An experimenter held up the calf so it stood on its 4 legs. The experimenter first placed the right hand on the calf's head with fingertips resting on the calf's lips for $20 \mathrm{~s}$. If the calf began lip-tongue movements, the experimenter waited until the end of the 20 -s period and placed a finger in the calf's mouth. The finger was left in the mouth until sucking by the calf was felt. The test was ended if the calf sucked for $5 \mathrm{~s}$. If the calf did not produce lip-tongue movements, the experimenter moved to the second phase, where the fingertips were moved over the calf's muzzle and lips for $20 \mathrm{~s}$. The test was ended if the calf sucked for $5 \mathrm{~s}$. If the calf did not produce lip or tongue movements or grasp the experimenter's finger to start sucking after $20 \mathrm{~s}$, the experimenter began the third phase by placing a finger in the calf's mouth. The test was ended if the calf sucked for $5 \mathrm{~s}$. If no sucking was observed, the experimenter lightly splashed milk over the calf's muzzle and re-introduced a finger in the calf's mouth for a maximum of $20 \mathrm{~s}$ or until the calf had sucked for $5 \mathrm{~s}$. If no sucking was observed after $20 \mathrm{~s}$, the test was ended. We measured the latency for each calf of when it first sucked.

\section{Statistical Analysis}

The GLM procedure of SAS (version 9.1, SAS Institute Inc., Cary, NC) was used to analyze the quantity of colostrum consumed during the first meal, the duration of the meal, the rate of consumption, and the duration of the sucking reflex test, with time since birth $(2 \mathrm{H}$ vs. $6 \mathrm{H})$ and presence or absence of a heat lamp (HL vs. no $\mathrm{HL}$ ) as factors and the interaction between time since birth and presence of a heat lamp. Calves were also scored for 1) sex (male vs. female); 2) being pulled at calving (pulled vs. not pulled); 3) having suckled their dam (suckled vs. not suckled); 4) vigor during the $1 \mathrm{~h}$ after birth (high: calf spent $>55 \%$ of the first hour after birth either walking, standing, or trying to stand vs. low: calf spent $<55 \%$ of the first hour after birth walking, standing, or trying to stand); and 5) vigor during colostrum feeding (high: calf stood for $>50 \%$ of the colostrum feeding period vs. low: calf stood for $<50 \%$ of the feeding period). The GLM procedure was used to examine the effects of the above variables on colostrum intake, meal duration, meal speed, and latency to suck. Pearson correlations between colostrum intake, meal duration, meal speed, latency to suck, and birth weight, rectal temperature and room temperature were calculated. Once independency among variables was established (using matrix of correlations and Chi-square contingency tables), multiple regression with PROC REG was used to determine which of these variables were the best predictors of colostrum intake, meal duration, meal speed, and sucking reflex. The data were checked for normality before analysis.

\section{RESULTS}

\section{Colostrum Intake}

Calves consumed (mean $\pm \mathrm{SD}$ ) $3.3 \pm 1.3 \mathrm{~L}$ of colostrum in $18 \pm 6 \mathrm{~min}$ at a rate of $0.21 \pm 0.18 \mathrm{~L} / \mathrm{min}$. However, there was a large difference among calves in the quantity of colostrum ingested (Figure 1); $22 \%$ of calves consumed less than $2 \mathrm{~L}$. There was no correlation between meal duration and colostrum intake $\left(\mathrm{r}^{2}\right.$ $=0.003 ; P>0.1)$. Neither time since birth nor provision of the heat lamp influenced colostrum intake, meal duration, or meal speed, and there was no interaction between time since birth and the presence of the heat lamp (Table 1).

Interventions at calving occurred in $64 \%$ of calvings and a pull took $4 \pm 12 \mathrm{~min}$ on average. The calf's 


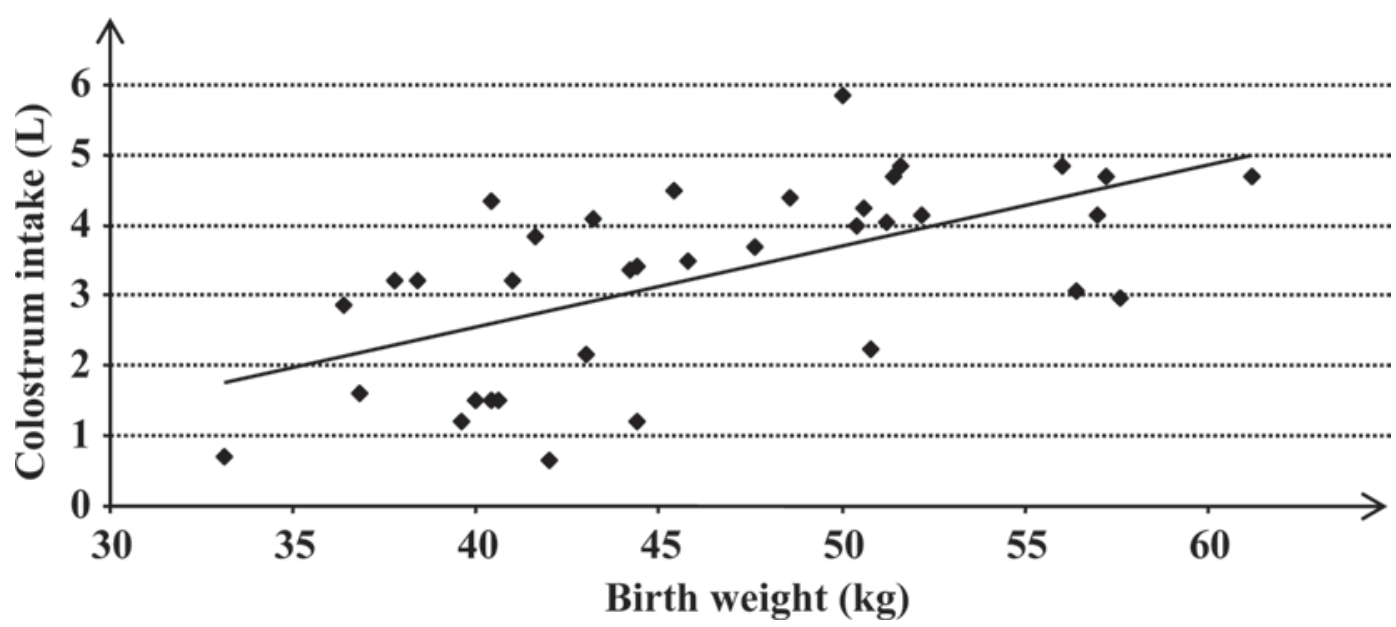

Figure 1. Relationship between calf's birth weight and colostrum intake $\left(\mathrm{r}^{2}=0.37 ; P<0.001\right)$. Each point represents an individual calf.

vigor both during the first hour after birth and during the colostrum feeding was associated with increased colostrum intake (Table 2). Greater vigor during the first hour after birth was related to increased meal speed. The quantity of colostrum ingested and the meal speed did not differ between males and females, between calves that were pulled or not pulled at calving, or between calves that suckled or did not suckle their dam (Table 2). The meal duration was shorter for males than females and longer for calves that had suckled their dam. No relationship was found between meal duration and any other variables $(P>0.1)$. Both the quantity of colostrum ingested and meal speed were correlated with birth weight (Table 3 ).

Rectal temperature (Table 3) was not correlated with the quantity of colostrum consumed but was higher for $2 \mathrm{H}$ calves $\left(38.4 \pm 0.7^{\circ} \mathrm{C}, P=0.002 ;\right.$ mean $\left.\pm \mathrm{SE}\right)$ than for $6 \mathrm{H}$ calves $\left(37.6 \pm 0.7^{\circ} \mathrm{C}\right)$ but no differences were found between heat lamp treatments $(P>0.1)$. Rectal temperature was not related to sex, being pulled at calving, having suckled, vigor during colostrum feeding, activity in the first hour of life, or birth weight $(P>$ 0.1 ). Room temperature was not correlated with colostrum intake but meal duration was longer when room temperature was lower (Table 3). Room temperature was not correlated with any other variable $(P>0.1)$.

The multiple regressions showed that the quantity of colostrum ingested was best predicted $\left(\mathrm{r}^{2}=0.61 ; \mathrm{df}=\right.$ $35 ; P<0.001)$ by a combination of birth weight $(\beta=$ $0.096 ; P<0.001)$, vigor during colostrum feeding $(\beta$ $=-1.282 ; P<0.001)$, and vigor during the first hour of life $(\beta=0.703 ; P=0.036)$, whereas meal duration was predicted $\left(\mathrm{r}^{2}=0.34 ; \mathrm{df}=34 ; P=0.002\right)$ jointly by room temperature $(\beta=-1.022 ; P=0.003)$ and having suckled the dam $(\beta=4.374 ; P=0.046)$.

\section{Sucking Reflex Test}

Calves took $42 \pm 16 \mathrm{~s}$ (mean $\pm \mathrm{SD})$ to start sucking on the fingers in the sucking reflex test. Neither time since birth nor provision of a heat lamp influenced the latency to suck, and there was no interaction between time since birth and the presence of the heat lamp $(P$ $>0.1$ ) (Table 1). There was no relationship between latency to suck in the sucking reflex test and colostrum intake $\left(\mathrm{r}^{2}=0.02 ; P>0.1\right)$, meal duration $\left(\mathrm{r}^{2}=0.01\right.$; $P>0.1)$, or meal speed in the feeding test $\left(\mathrm{r}^{2}=0.03\right.$; $P>0.1$ ). Latency to first suck did not differ (Table 2)

Table 1. Effects of time since birth (2 vs. 6 h) and presence (HL) or absence (no HL) of a heat lamp on colostrum intake, meal duration, and meal speed during the feeding test, and latency to suck during test of the sucking reflex ${ }^{1}$

\begin{tabular}{|c|c|c|c|c|c|c|c|}
\hline Item & \multicolumn{3}{|c|}{ Time since birth $(\mathrm{T})$} & \multicolumn{3}{|c|}{ Heat treatment $(\mathrm{H})$} & $\frac{P \text {-value }}{\mathrm{H} \times \mathrm{T}}$ \\
\hline Colostrum intake (L) & $3.1 \pm 0.3$ & $3.4 \pm 0.3$ & 0.5 & $3.3 \pm 0.3$ & $3.2 \pm 0.3$ & 0.8 & 0.2 \\
\hline Meal speed (L/min) & $0.22 \pm 0.04$ & $0.19 \pm 0.04$ & 0.6 & $0.24 \pm 0.04$ & $0.18 \pm 0.04$ & 0.3 & 0.2 \\
\hline Latency to suck (s) & $40.2 \pm 4.2$ & $45.0 \pm 4.0$ & 0.4 & $42.0 \pm 4.2$ & $43.3 \pm 4.0$ & 0.8 & 0.7 \\
\hline
\end{tabular}

${ }^{1} \mathrm{n}=18$ except for latency to suck during $2 \mathrm{~h}$ and HL treatments, where $\mathrm{n}=17$. Values are mean $\pm \mathrm{SE}$. 
between males and females, calves that were pulled or not pulled at calving, calves that suckled or did not suckle their dam, and there was no association with calf vigor. Latency to suck was not correlated (Table 3 ) with birth weight, rectal temperature, or room temperature $(P>0.1)$.

\section{DISCUSSION}

We found large variation among calves in the quantity of colostrum ingested; $22 \%$ of calves consumed $<2$ L. Previously, Franklin et al. (2003) also reported that $20 \%$ of calves were tube-fed because they consumed $<2.6 \mathrm{~L}$ during the first feeding. The unwillingness of calves to consume large quantities of colostrum from a bottle feeder may partly explain why many calves on dairy farms continue to receive inadequate colostrum (Kehoe et al., 2007; USDA, 2007).

The multiple regressions show that colostrum intake was best predicted by a combination of birth weight of the calf and the calf's degree of vigor based on its ability to stand, as used by Godfrey et al. (1991). The amount of colostrum consumed by calves was affected by their vigor, both at birth and at the time colostrum was given. A neonate must be sufficiently vigorous to be able to find the teat and ingest colostrum as soon as possible. Vitality and vigor are key survival characteristics for newborn calves, helping them reach a teat and ingest colostrum earlier (Nowak and Poindron, 2006; Baxter et al., 2008). Birth weight was an important factor affecting how much colostrum calves ingested, with large calves consuming more colostrum. Heavier lambs are reported to stand and find the udder sooner than newborns that weigh less (Nowak and Poindron, 2006), and heavier piglets suckle sooner after birth (Baxter et al., 2008). The birth weight and degree of vigor is a good indicator of a calf's capacity to ingest colostrum, and colostrum-feeding practices may need to be adapted to account for the calf's vigor.

We found no evidence that provision of a heat lamp or time since birth (2 h vs. $6 \mathrm{~h}$ ) affected the amount of colostrum consumed by the calves. Calves are born with little energy reserves and must counteract the heat loss associated with the transition from the warm uterine environment to a cold external environment by metabolizing brown fat reserves and by shivering (Nowak and Poindron, 2006). We expected that the loss of energy associated with thermoregulation would have reduced the calves' vigor, sucking motivation, and ability to ingest colostrum. We expected this to be most evident after $6 \mathrm{~h}$ and that this effect would be reduced by provision of a heat lamp. However, we did not find this. Rectal temperature of calves did decrease between 2 and $6 \mathrm{~h}$, but rectal temperature was not affected by 
Table 3. Relationship between rectal temperature, birth weight, and room temperature, and colostrum intake, meal duration, meal speed during feeding test, and latency to suck during test of sucking reflex ${ }^{1}$

\begin{tabular}{lccc}
\hline & \multicolumn{2}{c}{$\mathrm{r}^{2}$} \\
\cline { 2 - 4 } & $\begin{array}{c}\text { Rectal temperature } \\
(\mathrm{n}=36)\end{array}$ & $\begin{array}{c}\text { Birth weight } \\
(\mathrm{n}=36)\end{array}$ & $\begin{array}{c}\text { Room temperature } \\
(\mathrm{n}=34)\end{array}$ \\
\hline Item & 0.06 & $0.37^{* * *}$ & 0.01 \\
Melostrum intake (L) & 0.01 & 0.04 & $0.25^{* *}$ \\
Meal speed (L/min) & 0.06 & $0.18^{* *}$ & 0.04 \\
Latency to suck ${ }^{1}(\mathrm{~s})$ & 0.07 & 0.08 & 0.01 \\
\hline${ }^{1}$ For latency to suck, $\mathrm{n}=35$ for rectal temperature and birth weight, and $\mathrm{n}=33$ for room temperature; $\mathrm{n}=$ \\
number of calves per group.
\end{tabular}

the presence of the heat lamp and was not correlated with the amount of colostrum ingested. Provision of a heat lamp for $24 \mathrm{~h}$ has been found to be useful for resuscitating calves during the first $24 \mathrm{~h}$ (Uystepruyst et al., 2002). The lack of an effect of the heat lamp in increasing rectal temperature or colostrum intake could be because the weather was relatively warm, or perhaps provision of a heat lamp for only $1 \mathrm{~h}$ is not sufficient to help less vigorous calves.

Possibly, the extra time in contact with the dam of the $6 \mathrm{H}$ calves $(4 \mathrm{~h}$ vs. $1 \mathrm{~h}$ ) may have resulted in the calves receiving extra stimulation and heat from the dam, which may have compensated for the greater loss of energy. Alternatively, because calves suckle for the first time at $4 \mathrm{~h}$ on average (Selman et al., 1970; Ventorp and Michanek, 1991), the calves tested at $2 \mathrm{~h}$ after birth may have been too young to fully suck, which may have overshadowed any differences in the degree of vigor of the calves. These results suggest that calves are as ready to ingest colostrum at $2 \mathrm{~h}$ as at $6 \mathrm{~h}$ after birth.

We found no differences between male and female calves on colostrum intake, perhaps because of the lack of differences in the weights of males and females. Riley et al. (2004) found than Brahman male calves had greater odds of poor vigor (score based on capacity to nurse) than females but we found no sex differences in vigor.

No differences of colostrum intake, meal duration, or speed were found between calves that were pulled or not pulled at calving. Difficulties at calving could result in weak calves because of anoxia. Studies on pigs have shown that hypoxia during delivery reduces early postnatal vitality and delays the first intake of colostrum (Herpin et al., 1998). Pulling should be an indicator of difficulty at calving. However, $64 \%$ of our calves were pulled at birth, which suggests that pulling is part of the routine management on this farm and cannot be used as an indicator of birth difficulties.

No differences were found in colostrum intake between calves that suckled or did not suckle their mother, but calves that suckled their mother consumed for a longer time. This suggests that calves that suckled are not less able to consume colostrum from a bottle. However, only 7 calves were observed suckling, and we were unable to measure actual colostrum intake from the suckling, which limits the conclusions that we can draw. The finding that only one-third of calves left with their dams for more than $4 \mathrm{~h}$ were observed suckling is somewhat surprising because studies have shown that calves suckled for the first time at $4 \mathrm{~h}$ on average (Selman et al., 1970; Ventorp and Michanek, 1991) although the range among calves is large (from 50 to $720 \mathrm{~min}$; Ventorp and Michanek, 1991). However, prior suckling did increase the duration of the meal. The multiple regressions showed that meal duration was longer for female calves, calves having previously suckled, and when the room temperature was colder. Colostrum feeding by bottle took $18 \mathrm{~min}$ on average, which may be too time-consuming for routine management, although tube-feeding for colostrum is still a minor practice in North America (USDA, 2007; Vasseur et al., 2007).

The sucking reflex is reported to be present in utero in several species (Barcroft and Barton, 1939; Fraser and Broom, 1990), and piglet survival has been found to be affected by latency to suckle (Baxter et al., 2008). We developed a test of the sucking reflex based on previous work with lambs by Vince (1984), Vince et al. (1984), and Vince and Stanier (1991). We found differences among calves in the latency to first suck, but there were no effects of age or use of heat lamp, birth weight, vigor, sex, or temperature. There was no relationship between the time to first suck in the sucking reflex test and colostrum intake. The difficulty some calves have in ingesting sufficient colostrum does not seem to be linked to a weak sucking reflex.

\section{CONCLUSIONS}

A calf's voluntary intake of colostrum is mainly predictable by birth weight and the calf's vigor. This could help producers anticipate a calf's capacity to consume 
and adjust the feeding method appropriately. Calves' willingness to ingest colostrum intake was not reduced $6 \mathrm{~h}$ after birth, nor was it improved by the provision of heat for $1 \mathrm{~h}$.

\section{ACKNOWLEDGMENTS}

We thank Novalait (Quebec City, Quebec, Canada), Agriculture and Agri-Food Canada (Ottawa, Ontario, Canada), and the Natural Sciences and Engineering Research Council of Canada (Ottawa, Ontario, Canada) for their financial support, Nelson Dinn and the UBC Dairy Educational and Research Center staff (Agassiz, British Columbia, Canada) for help, Doug Veira (Agriculture and Agri-Food Canada, Agassiz, British Columbia, Canada) and Doris Pellerin (Laval University, Quebec City, Quebec, Canada) for helpful suggestions, Mairi Robertson (Agriculture and Agri-Food Canada, Agassiz, British Columbia, Canada) for her guidance, and Marie-Pierre Dallaire (Laval University, Quebec city, Quebec, Canada) for her excellent technical assistance.

\section{REFERENCES}

Alonso-Spilsbury, M., D. Mota-Rojas, D. Villanueva-Garci, J. MartinezBurnes, H. Orozco, R. Ramirez-Necoechea, A. L. Mayagoitia, and M. E. Trujillo. 2005. Perinatal asphyxia pathophysiology in pig and human: A review. Anim. Reprod. Sci. 90:1-30.

Azzam, S. M., J. E. Kinder, M. K. Nielsen, L. A. Werth, K. E. Gregory, L. V. Cundiff, and R. M. Koch. 1993. Environmental effects on neonatal mortality of beef calves. J. Anim. Sci. 71:282-290.

Barcroft, J., and D. H. Barton. 1939. The development of behaviour in foetal sheep. J. Comp. Neurol. 70:477-502.

Baxter, E. M., S. Jarvis, R. B. D'Eath, D. W. Ross, S. K. Robson, M. Farish, I. M. Nevison, A. B. Lawrence, and S. A. Edwards. 2008. Investigating the behavioural and physiological indicators of neonatal survival in pigs. Theriogenology 69:773-783.

Canadian Council on Animal Care. 1993. Guide to the Care and Use of Experimental Animals. Volume 1. CCAC, Ottawa, Ontario, Canada.

Filteau, V., E. Bouchard, G. Fecteau, L. Dutil, and D. DuTremblay. 2003. Health status and risk factors associated with failure of passive transfer of immunity in newborn beef calves in Québec. Can. Vet. J. 44:907-913.

Franklin, S. T., D. M. Amaral-Phillips, J. A. Jackson, and A. A. Campbell. 2003. Health and performance of Holstein calves that suckled or were hand-fed colostrum and were fed one of three physical forms of starter. J. Dairy Sci. 86:2145-2153.

Fraser, A. F., and D. M. Broom. 1990. Farm Animal Behaviour and Welfare. 3rd ed. Bailliere Tindall, London, UK.

Godfrey, R. W., S. D. Smith, M. I. Guthrie, R. L. Stanko, D. A. Neuendorff, and R. D. Randel. 1991. Physiological responses of newborn Bos indicus and Bos indicus $\times$ Bos taurus calves after exposure to cold. J. Anim. Sci. 69:258-263.

Herpin, P., F. Wosiak, J. Le Dividich, and R. Bertin. 1998. Effects of acute asphyxia at birth on subsequent heat production capacity in newborn pigs. Res. Vet. Sci. 66:45-49.

Kehoe, S. I., B. M. Jayarao, and A. J. Heinrichs. 2007. A survey of bovine colostrum composition and colostrum management practices on Pennsylvania dairy farms. J. Dairy Sci. 90:4108-4116.
Le Dividich, J., J. A. Rooke, and P. Herpin. 2005. Nutritional and immunological importance of colostrums for the new-born pig. J. Agric. Sci. 143:469-485.

Mee, J. F. 2004. Managing the dairy cow at calving time. Vet. Clin. Food. Anim. 20:521-546.

Norheim, K., and E. Simensen. 1985. An epidemiological study of factors affecting serum IgG levels in dairy calves. Nord. Vet. Med. $37: 121-135$.

Nowak, R., and P. Poindron. 2006. From birth to colostrum: Early steps leading to lamb survival. Reprod. Nutr. Dev. 46:431-446.

Olson, D. P., C. J. Papasian, and R. C. Ritter. 1980. The effects of cold stress on neonatal calves. 2. Absorption of colostrum immunoglobulins. Can. J. Comp. Med. 44:19-23.

Riley, D. G., C. C. Chase Jr., T. A. Olson, S. W. Coleman, and A. C. Hammond. 2004. Genetic and nongenetic influences on vigor at birth and preweaning mortality of purebred and high percentage Brahman calves. J. Anim. Sci. 82:1581-1588.

Selman, I. E., A. D. McEwan, and E. W. Fisher. 1970. Serum immune globulin concentration of calves left with their dams for the first two days of life. J. Comp. Pathol. 80:419-427.

Trotz-Williams, L. A., K. E. Leslie, and A. S. Peregrine. 2008. Passive immunity in Ontario dairy calves and investigation of its association with calf management practices. J. Dairy Sci. 91:3840-3849.

USDA, 2007. NAHMS Dairy 2007, Part I: Reference of dairy cattle health and management practices in the United States. USDA, Washington, DC.

Uystepruyst, Ch., J. Coghe, T. Dorts, N. Harmegnies, M. H. Delsemme, T. Art, and P. Lekeux. 2002. Effect of three resuscitation procedures on respiratory and metabolic adaptation to extra uterine life in newborn calves. Vet. J. 163:30-44.

Vasseur, E., F. Borderas, R. Cue, A. M. de Passillé, D. Lefebvre, D. Pellerin, J. Rushen, and K. Wade. 2008. Producers' use of calf rearing practices that impact calf health. Proc. 29th World Veterinary Congress, Vancouver, Canada.

Vasseur, E., F. Borderas, R. Cue, D. Lefebvre, D. Pellerin, J. Rushen, K. Wade and A. M. de Passillé. 2007. Calf rearing practices: First step in the development of a welfare monitoring system. Page 241 in Proc. 41st International Congress of the ISAE, Merida, Mexico.

Ventorp, M., and P. Michanek. 1991. The importance of udder and teat conformation for teat seeking by the newborn calf. J. Dairy Sci. $75: 262-268$.

Veronesi, M. C., P. Riccaboni, M. Faustiri, M. Battocchio, F. Cairoli, and M. Villani. 2005. Potential association between placental features and apgar scores after normal parturition in the Thoroughbred horse. J. Anim. Vet. Adv. 12:965-970.

Vince, M. A. 1984. Teat-seeking or pre-sucking behavior in newlyborn lambs: Possible effects of maternal skin temperature. Anim. Behav. 32:249-254.

Vince, M. A., and M. W. Stanier. 1991. The effect of food intake on young Soay and Clun Forest lambs' response to touch on the face. Appl. Anim. Behav. Sci. 30:87-96.

Vince, M. A., T. M. Ward, and M. Reader. 1984. Tactile stimulation and teat-seeking behavior in newly born lambs. Anim. Behav. 32:1179-1184.

Wells, S. J., D. A. Dargatz, and S. L. Ott. 1996. Factors associated with mortality to 21 days of life in dairy heifers in the United States. Prev. Vet. Med. 29:9-19.

Wendy, E. V. 1999. Peripartum asphyxia syndrome in foals. Pages 247-253 in Proc. Annual Convention of the AAEP, Albuquerque, NM.

Zaremba, W., W. M. Guterbock, and C. A. Holmberg. 1993. Efficacy of a dried colostrum powder in the prevention of disease in neonatal Holstein calves. J. Dairy Sci. 76:831-836. 